Supporting information

\title{
Poly(fluorene-alt-naphthalene diimide) as n-type polymer electrodes for energy storage
}

Kasturi T. Sarang ${ }^{\dagger}$, Andrea Miranda ${ }^{\ddagger}$, Hyosung An ${ }^{\dagger \#, ~ E u n-S u o k ~ O h}{ }^{\S}$, Rafael Verduzco ${ }^{*} \| \perp$, Jodie L. Lutkenhaus*†¥

${ }^{\dagger}$ Artie McFerrin Department of Chemical Engineering, Texas A\&M University, College Station, Texas 77843, United States

‡Department of Chemistry, Rice University, Houston, Texas 77005, United States

§School of Chemical Engineering, University of Ulsan, Ulsan 44611, South Korea

"Department of Materials Science and NanoEngineering, Rice University, Houston, Texas 77005, United States

${ }^{\perp}$ Department of Chemical and Biomolecular Engineering, Rice University, Houston, Texas 77005, United States

${ }^{\sharp}$ Department of Materials Science and Engineering, Texas A\&M University, College Station, Texas 77843, United States

\#Present address: Department of Materials Science and Engineering, University of Illinois at Urbana-Champaign, Urbana, Illinois 61801, United States 


\section{Synthesis of poly(fluorne-alt-napthalene diimide)}

The synthesis of PFNDI was adapted from reports in the literature..$^{12}$ Briefly, 9,9-dioctylfluorene2,7-diboronic acid bis(1,3-propanediol) ester (114.5 $\mathrm{mg}, 0.205 \mathrm{mmol})$ was combined with 4,9dibromo-2,7-bis(2-octyldodecyl)benzo[lmn][3,8]phenanthroline-1,3,6,8(2H,7H)-tetraone $\mathrm{mg}, 0.205 \mathrm{mmol}$ ) in a $20 \mathrm{~mL}$ microwave vial. For every $100 \mathrm{mg}$ of monomer, $1 \mathrm{~mL}$ of anhydrous toluene $(2 \mathrm{~mL})$ and $0.41 \mathrm{~mL}$ of triethylammonium hydroxide $(0.82 \mathrm{~mL})$ were added. A small amount of Aliquat 336 was added and the microwave vial was capped with a turnover septum stopper and purged with $\mathrm{N}_{2}$ for 20 minutes while stirring. The stopper was removed and the catalysts (tris(dibenzylideneacetone)dipalladium(0) (10.15 mg) and tri(o-tolyl)phosphine (11.8 $\mathrm{mg})$ ) were added. The mixture was stirred and purged in the open-ended vial for 5 minutes before sealing with the microwave vial cap.

The reaction was carried out in a microwave synthesizer (Biotage ${ }^{\circledR}$ Initiator+). The synthesis was carried out at $180{ }^{\circ} \mathrm{C}$ with "very high absorption". To avoid over-pressurizing the vial, the temperature was slowly increased from $160{ }^{\circ} \mathrm{C}$ to $180{ }^{\circ} \mathrm{C}$ over 12 minutes and held at $180{ }^{\circ} \mathrm{C}$ for $\sim 80$ minutes. The product was precipitated in cold methanol after removing the aqueous phase with a pipette and concentrating the solution slightly with compressed air. The filtered polymer was rinsed with deionized water and cold methanol two times each. The resulting product was dark red in color. The product underwent Soxhlet extraction with acetone, hexanes, and chloroform, in that order. $M_{n}=27.9 \mathrm{kDa}, M_{w}=41.0 \mathrm{kDa}$, and PDI $=1.47$ as determined by gel permeation chromatography calibrated with polystyrene standards (Figure S1a). The degree of polymerization of PFNDI is 25.3. ' $\mathrm{H}$ NMR (400 MHz, $\left.\mathrm{CDCl}_{3}\right), \delta(\mathrm{ppm}): 8.82(\mathrm{Ar}-\mathrm{H}), 7.93(\mathrm{Ar}-\mathrm{H})$, $7.49(\mathrm{Ar}-\mathrm{H}), 7.42(\mathrm{Ar}-\mathrm{H}), 4.07\left(\mathrm{Ar}-\mathrm{N}-\mathrm{CH}_{2}-\right), 2.00(-\mathrm{CH}-), 1.24\left(-\mathrm{CH}_{2}-\right), 1.16\left(-\mathrm{CH}_{2}-\right), 0.86\left(-\mathrm{CH}_{3}\right)$ (Figure S1b). The synthetic yield was $237 \mathrm{mg}$ (95\% yield accounting for the loss of reactive 
groups on the monomers) before Soxhlet extraction, with $20 \mathrm{mg}$ collected from the chloroform fraction after purification.
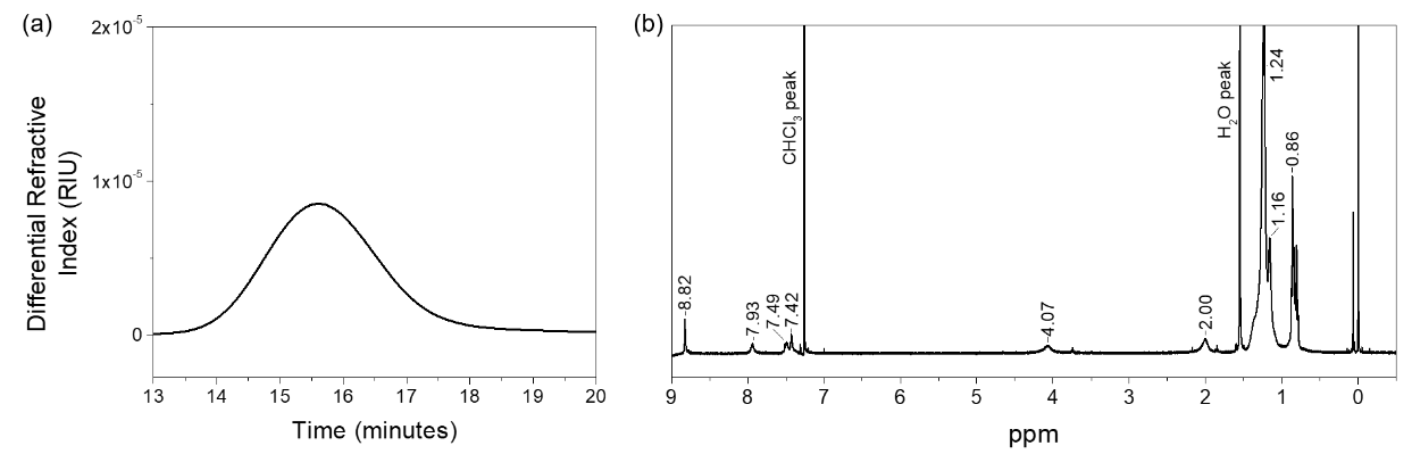

Figure S1. (a) GPC trace of the purified PFNDI product. (b) The 'H-NMR spectrum of PFNDI in deuterated chloroform. $M_{n}=27.9 \mathrm{kDa}, M_{w}=41.0 \mathrm{kDa}$, and PDI $=1.47$ as determined by GPC. The degree of polymerization is 25.3 .

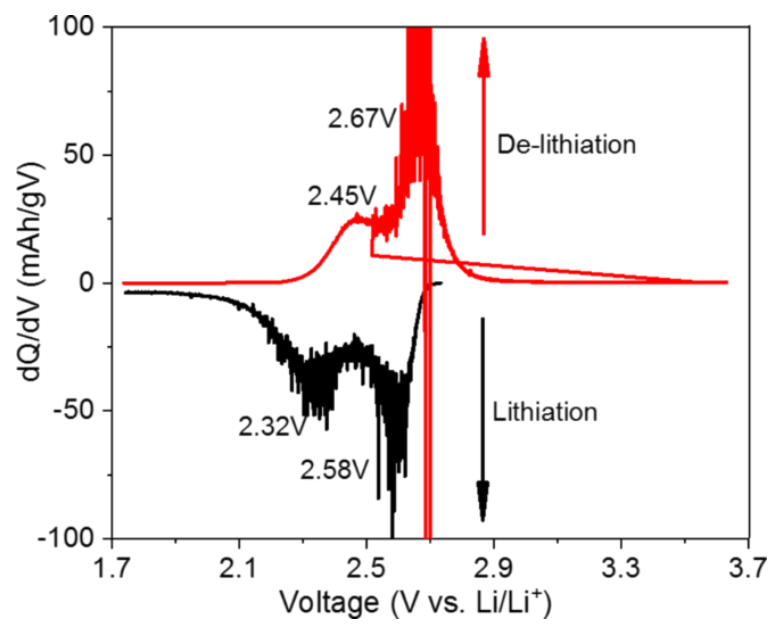

Figure S2. Differential capacity curve derived from potential curves at $1 \mathrm{C}$ in Figure $3 \mathrm{~b}$ in the main text. 


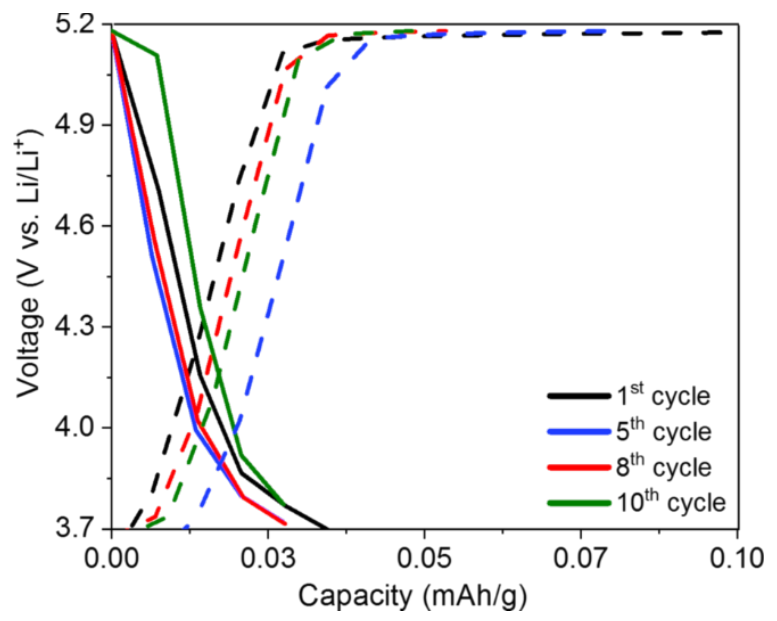

Figure S3. Galvanostatic charge-discharge at $1 \mathrm{C}$ for PFNDI polymer electrode at the $1^{\mathrm{n}}, 5^{\mathrm{h}}, 8^{\mathrm{m}}$ and $10^{\mathrm{m}}$ cycle in the high voltage region (HVR) from $3.7 \mathrm{~V}$ to $5.2 \mathrm{~V}$.

\section{Description of Calculations for Figure 5 in the main text}

We investigated Faradaic and non-Faradaic charge storage contributions for the PFNDI electrode. The current response $i(V)$ at different scan rates can be expressed as a sum of Faradaic $\left(\mathrm{a}_{1} \mathrm{v}^{\mathrm{os}}\right)$ and non-Faradaic $\left(\mathrm{a}_{2} \mathrm{v}\right)$ contributions as shown below.

$$
i(V)=a_{1} v^{0.5}+a_{2} v
$$

where $i(V)$ is the current response as a function of potential, $v$ is the scan rate, $a_{1}$ and $a_{2}$ are

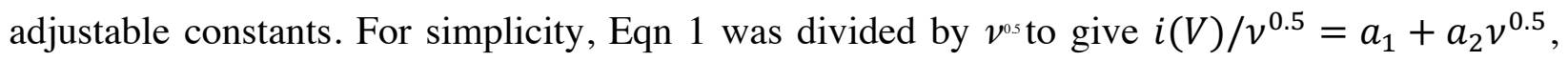
which was then plotted at different scan rates and different potentials as shown in Figure $5 \mathrm{a}, \mathrm{b}$ for anodic and cathodic scans respectively. $a_{1}$ (x-intercept) and $a_{2}$ (slope) were obtained by linear regression. Using these values, Faradaic $\left(a_{1} v^{o s}\right)$ and non-Faradaic $\left(a_{2} v\right)$ contributions were calculated at different potentials and plotted as shown in Figure 5c. The area under the CV plot (Figure 5c) was used to determine total charge stored and both the Faradaic and non-Faradaic contribution percentages (Figure 5d). 

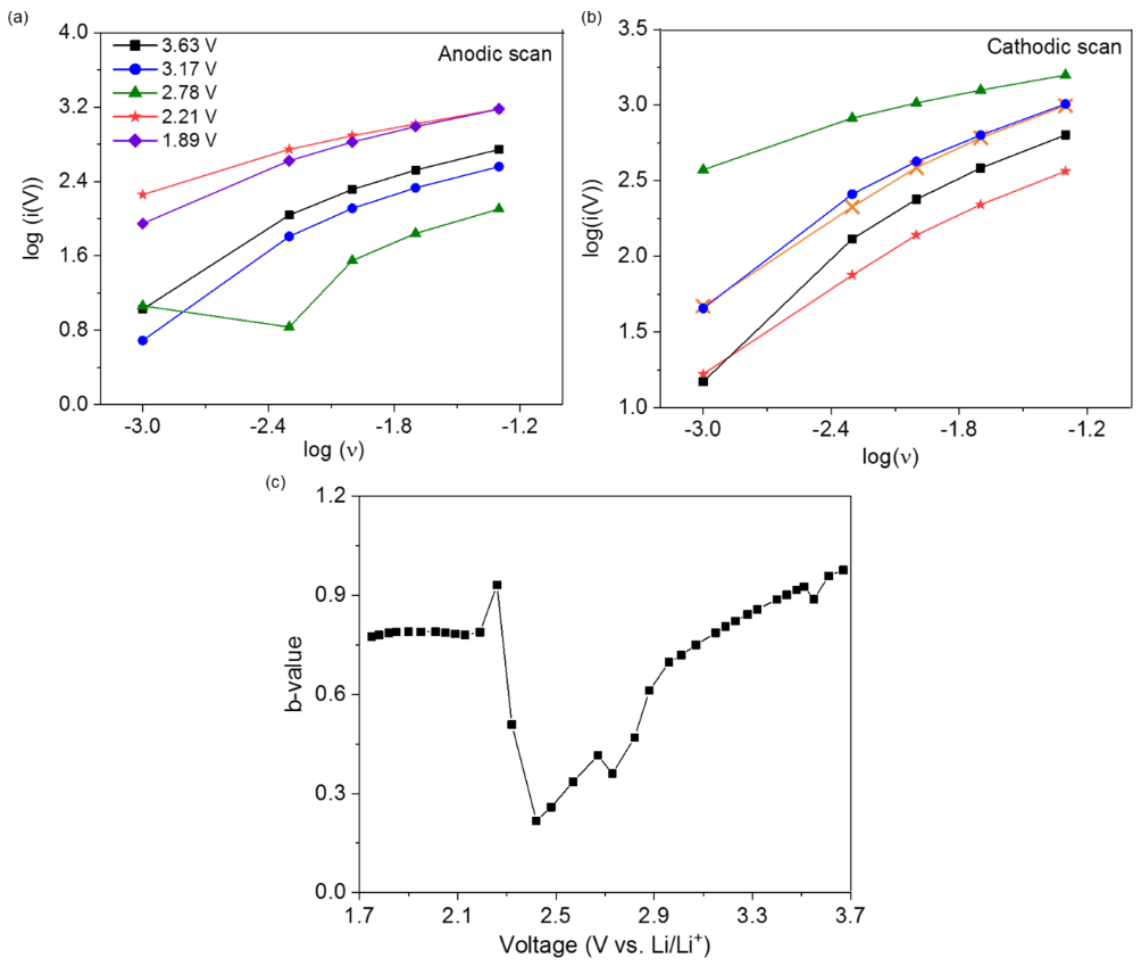

Figure S4. Plot of $\log (i(V)) v s . \log v$ for (a) anodic and (b) cathodic scans in cyclic voltammetry from which b-values of $\log (i(V))=b * \log v+\log a$ were calculated at different potentials. (c) A plot of b-value $v s$. potential.

The $b$-values were calculated using the equation $i(V)=a v^{b}$ as previously reported in literature. ${ }^{3}$ 


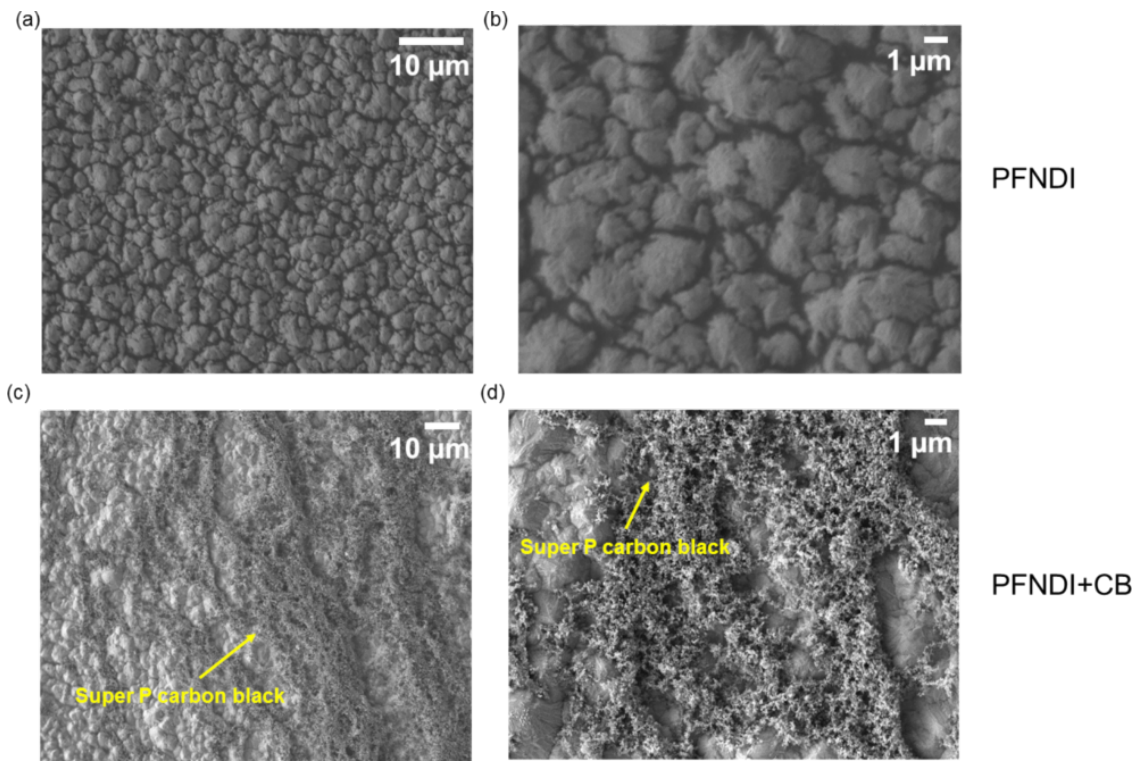

Figure S5. Scanning electron microscopy (SEM) of $(a, b)$ PFNDI and (c, d) PFNDI/CB=60/40 composite. The $b, d$ panel shows a magnified image of PFNDI and PFNDI/CB=60/40 respectively. Both PFNDI and PFNDI+CB were drop casted from chloroform (concentration of PFNDI was 0.3 $\mathrm{mg} / \mathrm{ml}$ ) onto cleaned copper foil substrate. They were dried at $50{ }^{\circ} \mathrm{C}$ to remove the residual solvent. A high resolution JEOL JSM-7500F equipment was used for SEM imaging. 

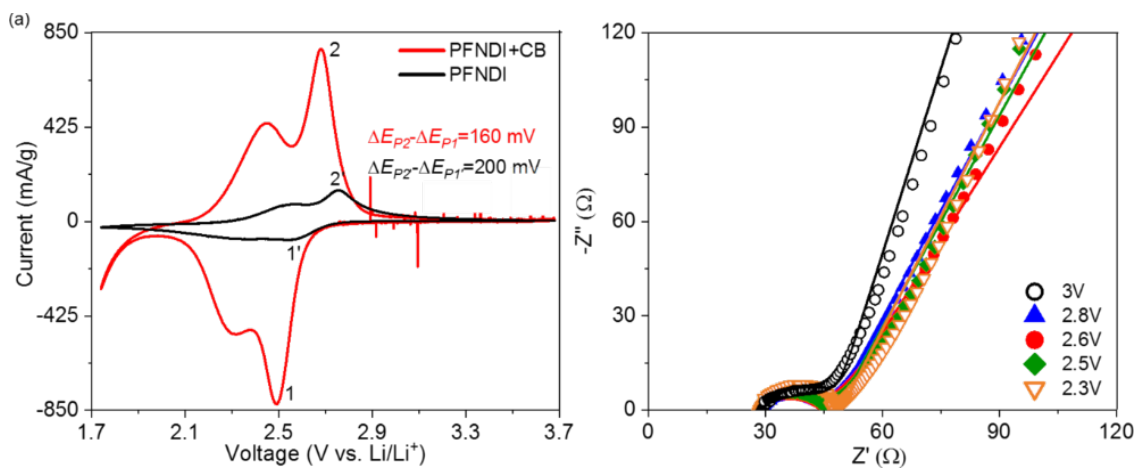

Figure S6. (a) Cyclic voltammogram at $1 \mathrm{mV} / \mathrm{s}$ for pure PFNDI polymer electrode (in black) and PFNDI+CB (carbon black) composite electrode (in red) in the low voltage region (LVR). Lower peak separation for PFNDI+CB $\left(\Delta E_{p}=160 \mathrm{mV}\right)$ implies enhanced electrochemical activity as compared to pure PFNDI $\left(\Delta E_{p}=220 \mathrm{mV}\right)$. (b) Nyquist plot for PFNDI+CB composite electrode at different potentials.
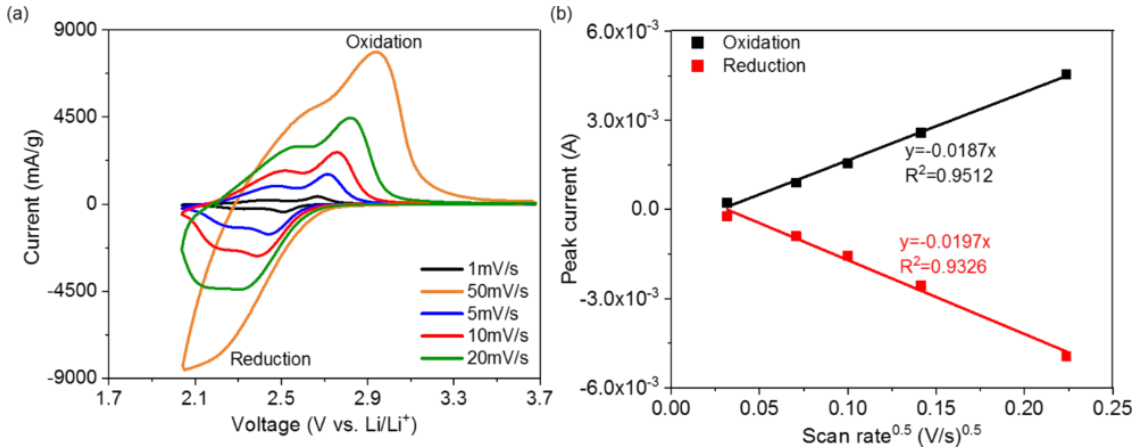

Figure S7. (a) Cyclic voltammogram of PFNDI+CB composite electrode at different scan rates in the LVR. (b) Plot of peak current $v s$. scan rate ${ }^{0.5}$ to calculate diffusion coefficient from the slope using the Randles-Sevcik equation. 
(a)

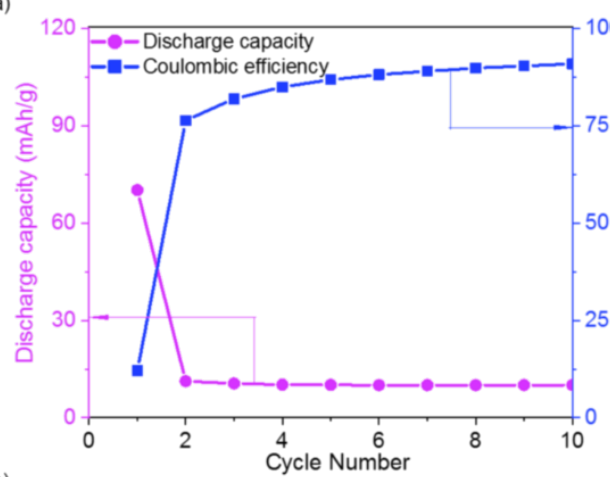

(c)

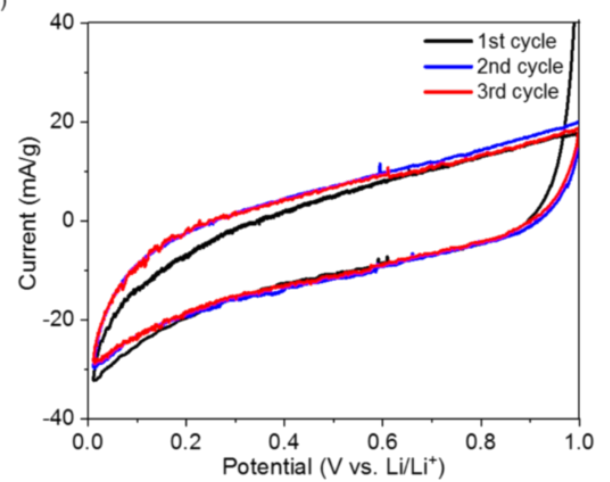

(b)

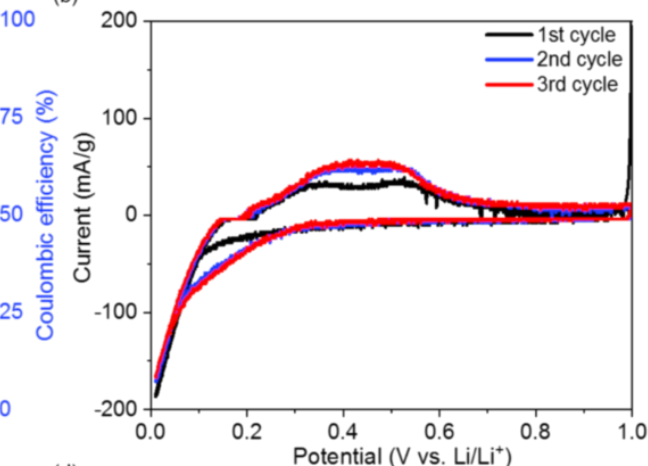

(d)

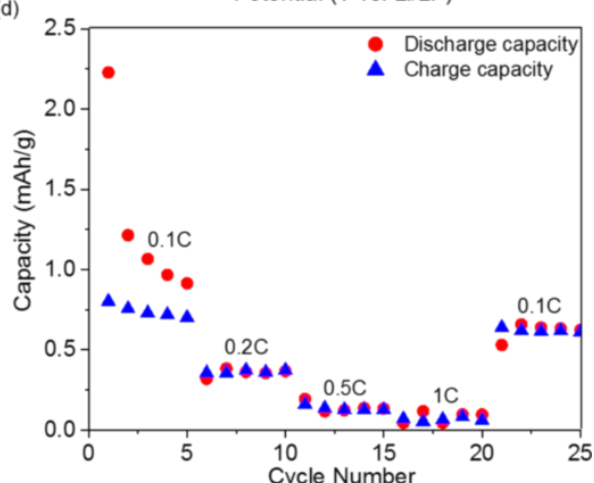

(e) 4500

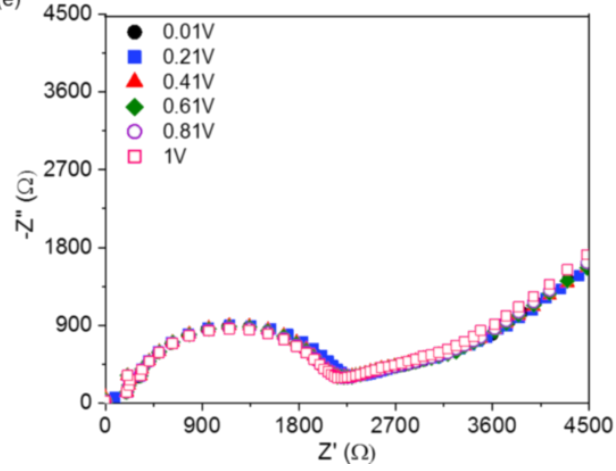

Figure S8. (a) Galvanostatic cycling performance and coulombic efficiency of $\mathrm{Si} / \mathrm{PFNDI} / \mathrm{CB}=65 / 15 / 20$ electrode at $0.1 \mathrm{C}$. (b) Cyclic voltammogram of the same electrode at 0.1 $\mathrm{mV} / \mathrm{s}$ for 3 cycles. (c) Cyclic voltammogram of pure PFNDI electrode at $1 \mathrm{mV} / \mathrm{s}$ for 3 cycles and (d) galvanostatic charge-discharge at difference C-rates from $0.1 \mathrm{C}$ to $1 \mathrm{C}$ (5 cycles each). (e) Electrochemical impedance spectroscopy of pure PFNDI at different potentials in $0.01 \mathrm{~V}$ to $1 \mathrm{~V}$ vs. $\mathrm{Li} / \mathrm{Li}^{+}$. The AC amplitude was $50 \mathrm{mV}$. The frequency range was from $100 \mathrm{kHz}$ to $5 \mathrm{mHz}$. All tests were carried out in $0.01 \mathrm{~V}$ to $1 \mathrm{~V} v s$. $\mathrm{Li} / \mathrm{Li}^{+}$voltage window. 
Table S1. A list of selected n-type polymers reported in literature.

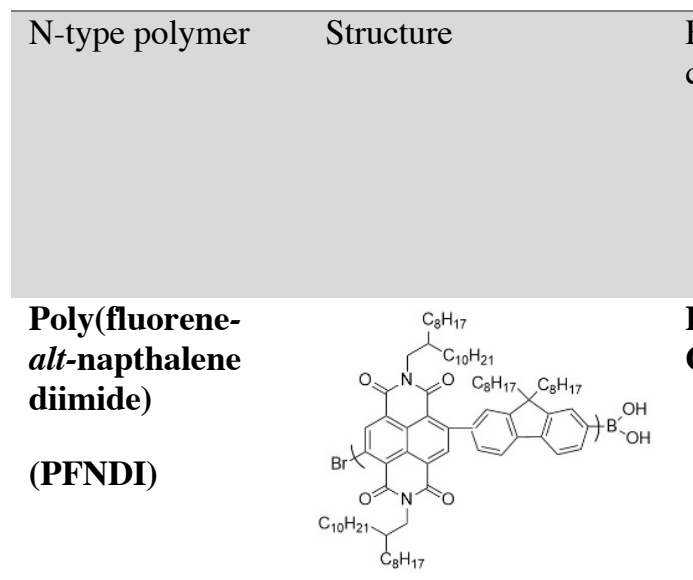

Poly(benzobisimi dazobenzophenant hroline)

(BBL)

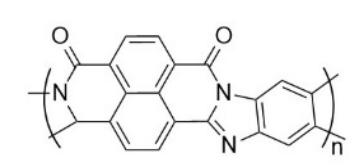

BBL:carbon

nanotubes $(\mathrm{CNT}): \mathrm{PVDF}=70$ :

20:10

Poly(paraphenylene)

(PPP)

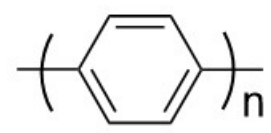

Poly(anthraquinonysulfide)

(PAQS)

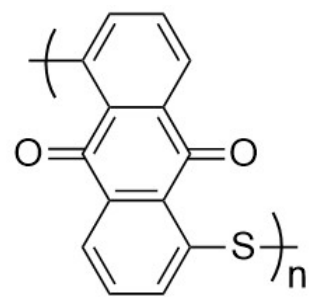

PPP:CNT:

$\mathrm{PVDF}=70: 20: 10$

$0.02-1.5 \quad 400$

$630,100,407$ $\mathrm{mA} / \mathrm{g}$

PAQS:AB:

PTFE $=40: 40: 20$

$1.4-3.2$

218

$75, \quad 50, \quad 50 \quad 8$ $\mathrm{mA} / \mathrm{g}$
Sodium poly[9,9bis(3propanoate)fluorine] (PF-COONa)

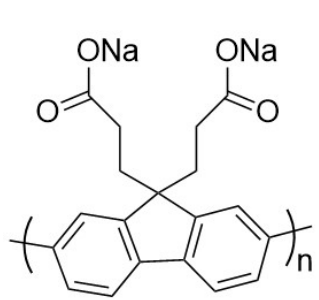

Pure polymer

$0.01-3.0 \quad 60.5$

$43.4,100,20 \quad 9$ $\mathrm{mA} / \mathrm{g}$ 


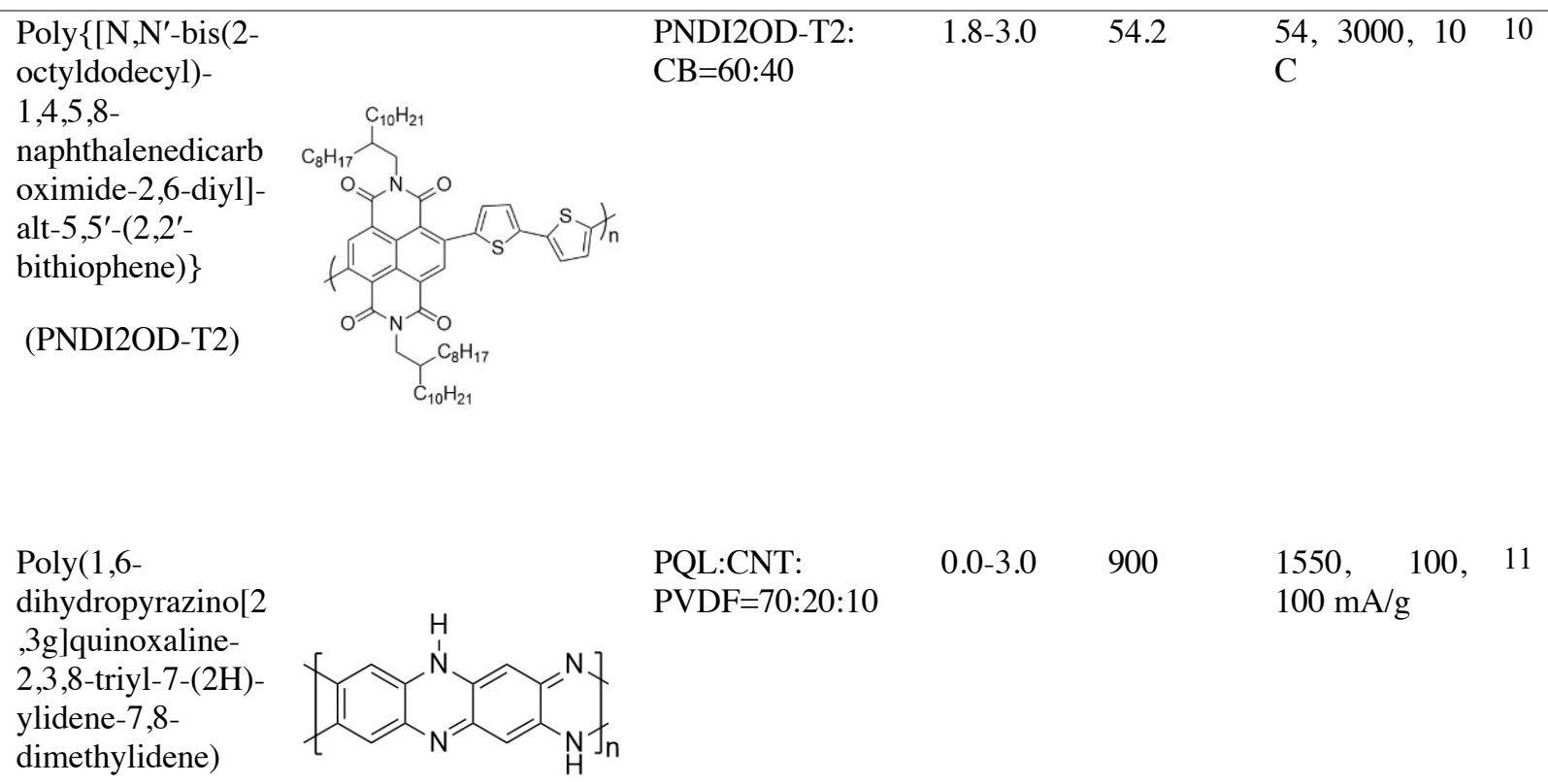

Poly $(1,6-$

dihydropyrazino[2 ,3g]quinoxaline2,3,8-triyl-7-(2H)ylidene-7,8dimethylidene)
$\begin{array}{llllll}\text { PQL:CNT: } & 0.0-3.0 & 900 & 1550, & 100, & 11\end{array}$ PVDF=70:20:10 $100 \mathrm{~mA} / \mathrm{g}$

(PQL)

Poly(benzo[1,2-

b:4,5-

$\mathrm{b}^{\prime}$ ]dithiophene4,8-dione-2,6-diyl sulfide<smiles>CC(C)(C)Sc1cc2c(s1)C(=O)c1sc(C(C)(C)C)cc1C2=O</smiles>

(PBDTDS)

$\operatorname{Poly}(2,5$ dihydroxyaniline)

(PDHA)<smiles>CCCCCNc1cc(O)c(C)cc1O</smiles>

PBDTDS:

$\mathrm{CNT}=80: 20$

PDHA:CB:PVDF $\quad 1.5-3.0$

$=60: 30: 10$

$1.9-3.2$

121

$138,250,0.1 \quad 12$

C

$100,50,0.1 \mathrm{C} \quad 13$

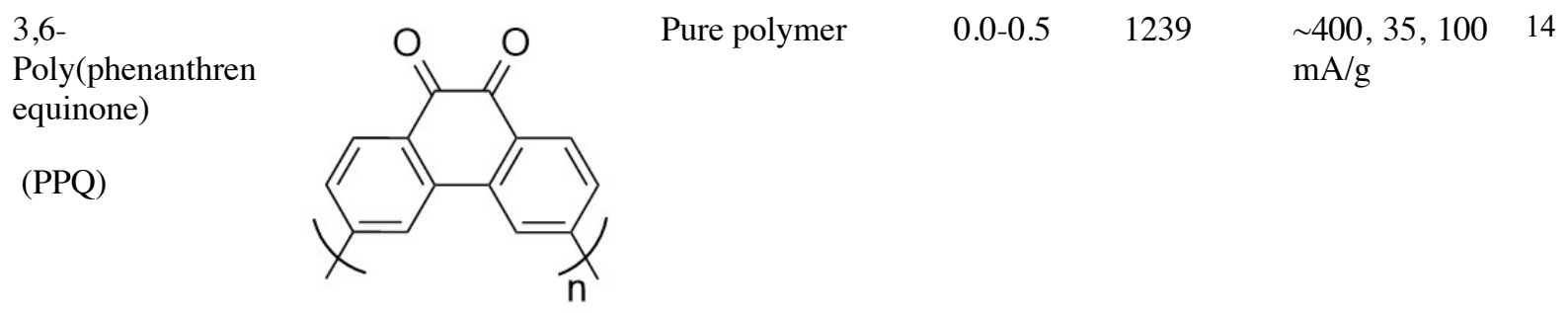




\section{Author information}

Corresponding author

Email: jodie.lutkenhaus@tamu.edu

\section{References}

1. Nam, S. Y.; Choi, E. Y.; Song, C. E.; Lee, C.; Jung, I. H.; Yoon, S. C., Naphthalenediimide-incorporated conjugated polyelectrolyte interfacial modifier for efficient inverted type polymer solar cells. J. Inf. Disp. 2016, 17, 17-24.

2. Zhou, E.; Cong, J.; Zhao, M.; Zhang, L.; Hashimoto, K.; Tajima, K., Synthesis and Application of Poly(fluorene-alt-naphthalene diimide) as an N-type Polymer for All-Polymer Solar Cells. Chem. Commun. 2012, 48 (43), 5283-5.

3. An, H.; Li, X.; Chalker, C.; Stracke, M.; Verduzco; Lutkenhaus, J. L., Conducting Block Copolymer Binders for Carbon-Free Hybrid $\mathrm{V}_{2} \mathrm{O}_{5}$ cathode with enhanced performance. ACS Appl. Mater. Interfaces 2016, 8, 28585-28591.

4. Augustyn, V.; Come, J.; Lowe, M. A.; Kim, J. W.; Taberna, P. L.; Tolbert, S. H.; Abruna, H. D.; Simon, P.; Dunn, B., High-rate Electrochemical Energy Storage through Li+ Intercalation Pseudocapacitance. Nat. Mater. 2013, 12 (6), 518-22.

5. Lindstrom, H.; Sodergren, S.; Solbrand, A.; Rensmo, H.; Hjelm, J.; Hagfeldt, A.; Lindquist, S.-E., Li+ Ion Insertion in TiO2 (Anatase). 2. Voltammetry on Nanoporous Films. J. Phys. Chem. B 1997, 101 (39), 7717-7722. 
6. Wu, J.; Rui, X.; Wang, C.; Pei, W.-B.; Lau, R.; Yan, Q.; Zhang, Q., Nanostructured Conjugated Ladder Polymers for Stable and Fast Lithium Storage Anodes with High-Capacity. Adv. Energy Mater. 2015, 5, 1402189.

7. Zhu, L. M.; Lei, A. W.; Cao, Y. L.; Ai, X. P.; Yang, H. X., An All-Organic Rechargeable Battery Using Bipolar Polyparaphenylene as a Redox-active Cathode and Anode. Chem. Commun. 2013, $49(6), 567-9$.

8. Song, Z.; Zhan, H.; Zhou, Y., Anthraquinone Based Polymer as High Performance Cathode Material for Rechargeable Lithium Batteries. Chem. Commun. 2009, (4), 448-50.

9. Liu, D.; Zhao, Y.; Tan, R.; Tian,L.-L.; Liu, Y.; Chen, H.; Pan, F., Novel Conductive Binder for High-Performance Silicon Anodes in Lithium Ion Batteries. Nano Energy 2017, 36, 206-212.

10. Liang, Y.; Chen, Z.; Jing, Y.; Rong, Y.; Facchetti, A.; Yao, Y., Heavily n-Dopable piConjugated Redox Polymers with Ultrafast Energy Storage Capability. J. Am. Chem. Soc. 2015, $137(15), 4956-9$.

11. Wu, J.; Rui, X.; Long, G.; Chen, W.; Yan, Q.; Zhang, Q., Pushing Up Lithium Storage through Nanostructured Polyazaacene Analogues as Anode. Angew. Chem., Int. Ed. Engl. 2015, $54(25), 7354-8$.

12. Jing, Y.; Liang, Y.; Gheytani, S.; Yao, Y., Cross-Conjugated Oligomeric Quinones for High Performance Organic Batteries. Nano Energy 2017, 37, 46-52.

13. Vlad, A.; Arnould, K.; Ernould, B.; Sieuw, L.; Rolland, J.; Gohy, J.-F., Exploring the Potential of Polymer Battery Cathodes with Electrically Conductive Molecular Backbone. J. Mater. Chem. A 2015, 3, 11189-11193. 
14. Kim, S. M.; Kim, M. H.; Choi, S. Y.; Lee, J. G.; Jang, J.; Lee, J. B.; Ryu, J. H.; Hwang, S. S.; Park, J. H.; Shin, K.; Kim, Y. G.; Oh, S. M., Poly(phenanthrenequinone) as a Conductive Binder for Silicon Anodes. Energy Environ. Sci. 2015, 8, 1538-1543. 